\title{
A utilização do HBIM na modelagem do prédio Solar da Beira em Belém/PA para
}

\section{registro digital}

The use of HBIM in the modeling of the Solar da Beira building in Belém/PA for digital registration

El uso de HBIM en el modelado del edificio Solar da Beira en Belém/PA para grabación digital

\section{Resumo}

O Building Information Modeling (BIM) é uma tecnologia de modelagem aplicada nos setores da Arquitetura, Engenharia e Construção (AEC). Refere-se a um programa de modelagem tridimensional representativo que engloba um conjunto de tecnologias e ações que permitem gerenciar o ciclo de vida de um edifício. Já o Historic Building Information Modeling (HBIM), é uma extensão do conceito BIM aplicado a edificações existentes, principalmente históricas, que visa a documentação, análise e conservação dessas construções. Tendo em vista que no Brasil existem muitos prédios históricos sem registros nas bibliotecas BIM, ou seja, não possuem informações sobre sua construção nem modificações sofridas no decorrer dos anos. Este trabalho teve como objetivo a realização da modelagem do prédio Solar da Beira, localizado na cidade de Belém do Pará, com a finalidade de descrever e discutir os procedimentos adotados e analisar as facilidades e dificuldades encontradas durante o processo. Assim como, enfatizar e entender a importância da utilização do HBIM em edificações históricas. O método se deu inicialmente através de uma revisão bibliográfica, posteriormente foram realizadas inspeções técnicas e levantamento de dados através de plantas baixas e cortes que foram submetidos a modelagem. Com isso, foi possível registrar os dados construtivos da edificação e disponibilizá-los para que os estudos desse prédio e possíveis futuras intervenções e preservação sejam facilitadas.

Palavras-chave: HBIM; Patrimônio Histórico; Solar da Beira.

\begin{abstract}
Building information modeling (BIM) is a modeling technology applied in the Architecture, Engineering and Construction (AEC) industry. It refers to a representative three-dimensional modeling program that includes a set of technologies and actions that allow managing the life cycle of a building. HBIM, on the other hand, which is an extension of the BIM concept applied to existing buildings, mainly historic ones, aiming to document, analyze and preserve these constructions. However, in Brazil there are many historic buildings without records in the BIM libraries, in other words, they do not have information about their construction or changes carried out over the years. This work aims to perform the modeling of the Solar da Beira building, located in Belém do Pará, in order to describe and discuss the procedures adopted and analyze the facilities and difficulties encountered during the process. As well as, emphasize and understand the importance of using HBIM in historic buildings. The method was based on literature review, technical inspections and data collection through floor plans and sections that were subjected to modeling.
\end{abstract}


Thus, it was possible to record the construction data of the building and make them available so that studies of this building and possible future interventions and preservation are facilitated.

Keywords: HBIM; Historical Heritage; Solar da Beira.

\begin{abstract}
Resumen
Building Information Modeling (BIM) es una tecnología de modelado aplicada en los sectores de Arquitectura, Ingeniería y Construcción (AEC). Se refiere a un programa representativo de modelado tridimensional que abarca un conjunto de tecnologías y acciones que le permiten administrar el ciclo de vida de un edificio. El Historic Building Information Modeling (HBIM), una extensión del concepto BIM aplicado a edificios existentes, principalmente históricos, que tiene como objetivo la documentación, análisis y conservación de estas construcciones. Teniendo en cuenta que en Brasil hay muchos edificios históricos sin registros en las bibliotecas BIM, es decir, no tienen información sobre su construcción o modificaciones sufridas a lo largo de los años. Este trabajo tuvo como objetivo realizar el modelado del edificio Solar da Beira, ubicado en la ciudad de Belém do Pará, con el fin de describir y discutir los procedimientos adoptados y analizar las instalaciones y dificultades encontradas durante el proceso. Así como, para enfatizar y comprender la importancia de usar HBIM en edificios históricos. El método se realizó inicialmente a través de una revisión de la literatura, y posteriormente las inspecciones técnicas y la recopilación de datos se realizaron a través de plantas bajas y cortes que se sometieron a modelado. Así, se ha podido registrar los datos constructivos del edificio y ponerlos a disposición para que se faciliten los estudios de este edificio y posibles intervenciones y conservación futuras.
\end{abstract}

Palabras clave: HBIM; Patrimonio histórico; Solar da Beira.

\title{
1. Introdução
}

A UNESCO (1972) define Patrimônio Cultural como "Grupos de construções isoladas ou reunidos que, em virtude da sua arquitetura, unidade ou integração na paisagem têm valor universal excepcional do ponto de vista da história, da arte ou da ciência”. Já a documentação de um bem cultural tem como finalidade conservar a imagem e a história deste, visando a sua preservação. Além disso, segundo Amorim (2008) "dada a falta de reconhecimento da importância destes bens por grande parte da população, a documentação encerra um significativo papel na construção da compreensão do valor do patrimônio arquitetônico brasileiro". Deste modo, documentar as informações da edificação é de suma importância para a sua preservação e conservação de seu valor cultural e material.

De acordo Eastman et al. (2018), o Building Information Modeling (BIM) é uma tecnologia de modelagem e um grupo associado de processos para produção, comunicação e análise do modelo de construção. Trata-se de um conjunto de informações gráficas e não gráficas que o objeto possui agregado à sua forma. Com esse conjunto de informações agregados a esse objeto consegue-se saber graficamente de quais materiais ele é constituído, suas dimensões e as áreas.

O Historic Building Information Modeling (HBIM) é aplicado a edificações existentes, principalmente históricas, que visa a documentação, análise e conservação dessas construções. A partir dele pode ser feita a modelagem por ferramentas para que assim se tenham registros construtivos recentes e alocados em um só ponto, para que isso seja realizado, é necessário também catalogar informações históricas sobre a edificação

Desta forma, este trabalho teve como objetivo a realização da modelagem do prédio Solar da Beira, localizado na cidade de Belém do Pará, no Complexo Ver-o-Peso. Trata-se de uma edificação secular, sendo construído em 1883 e tombado pelo IPHAN em 1977, passando por vários processos de reconstrução e restauro.

Para o desenvolvimento deste trabalho, foi realizada a modelagem do Prédio do Solar da Beira através do programa REVIT, descrevendo e discutindo todos os procedimentos adotados e analisando as facilidades e dificuldades encontradas durante esse processo. Antecedendo a modelagem da edificação, foi registrado seu perfil histórico para compreender seu contexto de participação na cidade.

\section{Metodologia}

Segundo Costa et al. (2021) "vários estudos descrevem processos para a documentação do patrimônio histórico por 
meio do HBIM (Fai e Rafeiro, 2014; Ciribini, Ventura e Paneroni, 2015; Brusaporci, Maiezza e Tata, 2018)”. Esses processos foram utilizados como base no presente trabalho que se deu-se na seguinte forma:

- Na etapa 1, foram realizadas buscas em bases de dados para uma revisão bibliográfica, a fim de conceituar o BIM e HBIM e entender seu processo de modelagem;

- A etapa 2, se deu através de visitas para realização de inspeções, com registros fotográficos e também levantamento de informações, como a obtenção de projetos do local;

- Na etapa 3, foi utilizado o software REVIT, pertencente ao grupo Autodesk. A escolha por este software se deu por conta da maior gama de conhecimento disponível publicamente e pelo fácil acesso a ele através de licença estudantil. Através disso, a modelagem foi feita utilizando as três famílias que esse software possui para a criação de modelos BIM, sendo estas: famílias de sistema, famílias carregáveis e famílias no local.

E estruturados conforme Figura 1.

Figura 1: Etapas do Método.

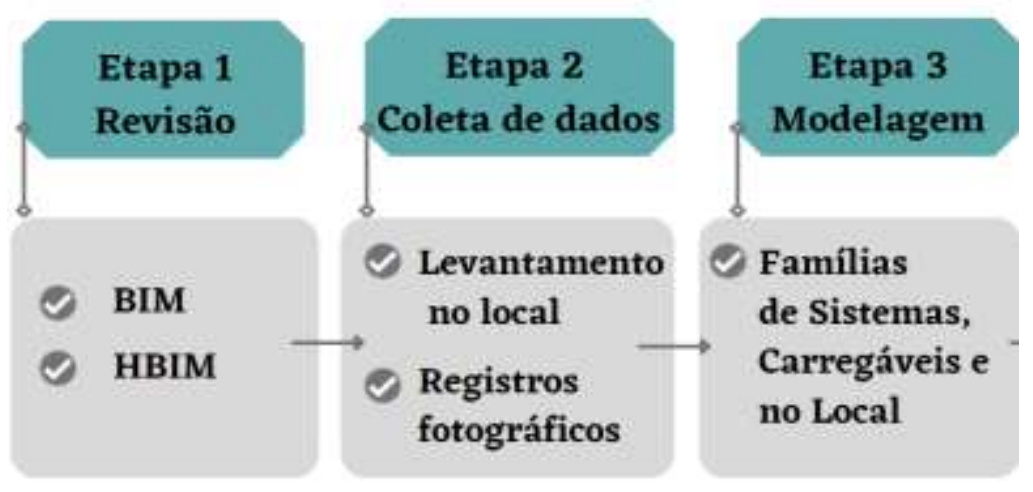

Fonte: Autores.

\subsection{BIM e modelagem de elementos históricos com o HBIM}

\subsubsection{BIM}

O BIM de acordo com Eastman et al. (2018) é uma tecnologia de modelagem e um grupo associado de processos para produção, comunicação e análise do modelo de construção. É aplicada na indústria da Arquitetura, Engenharia e Construção (AEC). Ele busca possibilitar a construção um 'modelo único de edifício a partir de uma prática de projeto integrada contando com todos os membros da AEC (Andrade et al., 2009). Refere-se a um programa de modelagem tridimensional representativa que engloba um conjunto de tecnologias e ações que permitem reunir informações gráficas e não gráficas que um objeto de estudo possui agregado a sua forma, resultando em uma visualização repleta de detalhes.

\subsubsection{HBIM}

É uma extensão do conceito BIM aplicado a edificações existentes, principalmente históricas, que visa a documentação, análise e conservação dessas construções e que utiliza um caminho inverso ao BIM para resguardar e analisar informações de um prédio já edificado. Apesar de o HBIM não participar das fases iniciais da execução do edifício, como projeto e construção, seu levantamento cadastral serve para embasar projetos de restauro e manutenção do edifício (Tolentino, 2018).

A fase prática de modelagem possui desafios na reconstrução de projetos, principalmente durante a modelagem dos elementos virtuais, que são as famílias paramétricas, esse termo refere-se a uma representação gráfica de uma classe de objetos 
ou componentes. Essas famílias de edifícios históricos são escassas nas bibliotecas BIM, já que se trata de elementos únicos e exclusivos, sendo assim, é imprescindível o domínio de ferramentas que auxiliem na construção e desenvolvimento da modelagem.

\subsubsection{Edifícios Históricos}

UNESCO (1972) define Patrimônio Cultural como: "Grupos de construções isoladas ou reunidos que, em virtude da sua arquitetura, unidade ou integração na paisagem têm valor universal excepcional do ponto de vista da história, da arte ou da ciência".

Segundo Pereira (2015): “a falta de informação sobre os edificados pode resultar numa ineficaz gestão do edifício e em perda de tempo ou incremento de custos na manutenção e em intervenções deste gênero". Então, quando obtemos um melhor registro virtual com informações construtivas mais precisamente de uma edificação histórica, sua conservação e restauro se torna mais acertada, além de haver a continuidade do valor histórico por mais gerações. Com isso, documentar as informações da edificação é de suma importância para a sua preservação e conservação de seu valor cultural e material.

\subsubsection{Solar da Beira}

É um prédio histórico pertencente ao complexo arquitetônico e paisagístico do Ver-o-Peso, foi tombado pelo IPHAN em 1977 e é protegido pela FUMBEL (Fundação Cultural do Município de Belém), por pertencer ao centro histórico da cidade de Belém. Conta com uma área construída de 1.149,72 m2, dividido em dois pavimentos e um mezanino. Localiza-se na Avenida Castilhos França, em frente ao Mercado Municipal e ao lado do Mercado de Ferro. Trata-se de uma edificação em alvenaria de tijolos, de sistema construtivo tradicional e autoportante, conta com fachada pouco ornamentada, e os vãos centrais maiores que os demais, todos em arco pleno, sendo platibanda triangulada e possuindo um relógio em seu vértice central.

O prédio foi utilizado inicialmente como o novo prédio da Recebedoria de Renda, voltado para fins de controle fiscal, com suas obras iniciadas em 1883 e entrega provisória em 1886, considerado uma obra célebre à época. Construído em estilo neoclássico, com dois andares, contava com um anexo situado entre o prédio principal e o mercado de ferro, que com o passar dos anos deu lugar ao setor de ervas da feira. Após sua construção, houve reformas pontuais, sendo a de maior relevância a ocorrida no governo de Almir Gabriel (1983-1986), na qual, juntamente com o restauro do Complexo do Ver-o-Peso, o prédio em questão passou por mudanças, sofrendo sua maior intervenção direta e, a partir deste período, passou a ser chamado de Solar da Beira. A próxima intervenção, ocorreu na gestão do prefeito Edmilson Rodrigues que mudou a paisagem da edificação, a qual passou a se apresentar da maneira que é conhecida atualmente. Com o passar do tempo, o prédio foi abandonado novamente e sofreu nova ação de órgãos públicos, com o processo de reforma e restauro entregue em 11 de novembro de 2020.

A escolha desta edificação se deu pelo recente processo de reforma ter favorecido o acesso a documentos mais atuais do prédio e seus desdobramentos. Para a elaboração da modelagem foram utilizados apenas os projetos arquitetônicos, sendo as plantas baixas fornecidas pela SEURB (Secretaria Municipal de Urbanismo), além de consulta de arquivos anexos ao processo de licitação.

\subsubsection{O uso do HBIM na edificação estudada}

Através de dados registrados das plantas baixas e cortes arquitetônicos do patrimônio como base para transformar esses dados em elementos BIM. A transição de um modelo 2D para uma modelagem 3D irá propiciar uma melhor análise e compreensão do prédio, através da comparação entre os arquivos virtuais com a edificação em si. 
Para a criação do modelo foram utilizadas somente as plantas baixas e de detalhes dos projetos arquitetônicos, conforme Tabela 1.

O presente trabalho utilizou todas as famílias para a modelagem, sendo elas: (i) as famílias de sistemas, que estão hospedadas no software, foram utilizadas para grande parte do sistema estrutural, como vigas e afins; (ii) as famílias carregáveis, que podem ser obtidas pelos fabricantes ou em bibliotecas de modelos BIM, foram utilizadas em detalhes hidráulicos, portas e divisórias presentes no banheiro; (iii) as famílias do local, apesar de demandar um grande esforço para essa modelagem, elas foram utilizadas nas esquadrias presentes na edificação.

Tabela 1: Listagem das plantas e detalhes.

\begin{tabular}{ccccc}
\hline Tipo & Numeração & Nome & Versão & Data \\
\hline Planta Baixa & 1 & Planta de Situação e Locação & R00 & jun/16 \\
Planta Baixa & 2 & Quiosque & R00 & jun/16 \\
Planta Baixa & 3 & Planta Pav. Térreo e Mezanino & R00 & jun/16 \\
Planta Baixa & 4 & Planta Pav. Superior e Cobertura & R00 & jun/16 \\
Planta Baixa & 5 & Planta Piso e Forro & R00 & jun/16 \\
Planta Baixa & 6 & Secções A, B e C & R00 & jun/16 \\
Planta Baixa & 7 & Elevações 01, 02, 03 e 04 & R00 & jun/16 \\
Planta Baixa & 8 & Layout Pav. Térreo e Mezanino & R00 & jun/16 \\
Planta de Detalhe & 9 & Esquadrias & R00 & jun/16 \\
Planta de Detalhe & 10 & Esquadrias & R00 & jun/16 \\
Planta de Detalhe & 11 & Banheiros & R00 & jun/16 \\
Planta de Detalhe & 12 & Banheiros & R00 & jun/16 \\
Planta de Detalhe & 13 & Banheiros & R00 & jun/16 \\
Planta de Detalhe & 14 & Banheiros & R00 & jun/16 \\
Planta de Detalhe & 15 & Paginação do piso & R00 & jun/16 \\
Planta de Detalhe & 16 & Rampa Metálica & R00 & jun/16 \\
Planta de Detalhe & 17 & Detalhes Lanternim & R00 & jun/16 \\
Planta de Detalhe & 18 & Detalhes condutor & R00 & jun/16 \\
Planta de Detalhe & 19 & R00 & jun/16 \\
\hline
\end{tabular}

Fonte: Autores.

\section{Resultados e Discussão}

\subsection{Levantamento de dados}

Durante a análise de projetos e inspeções foi possível identificar a existência de diferenças no detalhamento arquitetônico entre os cortes e fachadas com o edifício em construído. Na Figura 2 é possível identificar a ausência da moldura no pavimento superior detalhado na planta de elevações, porém é existente na edificação. Já na Figura 3 é possível notar a adição de detalhes da planta baixa dos pilares da fachada principal, detalhe que não existe na planta de elevações (Figura 2) e nem no prédio construído. 
Figura 2: Divergência entre projeto arquitetônico e levantamento in loco.

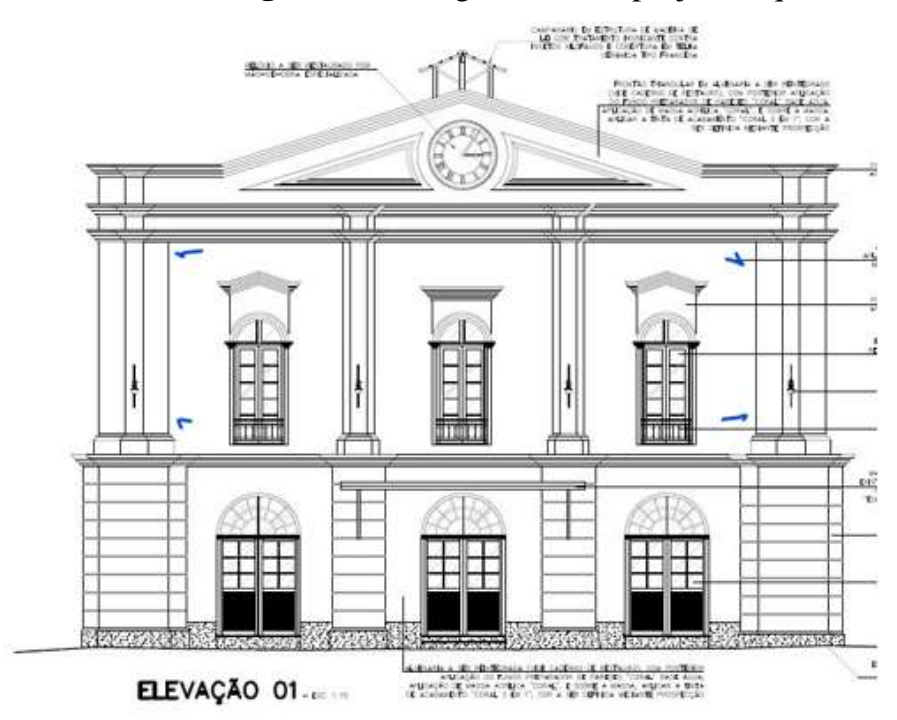

(a) Elevação 01 (Fachada Principal).

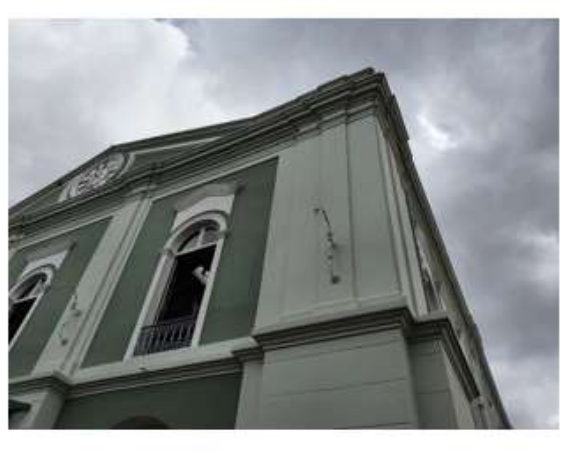

(b) Registro in loco.

Fonte: a) SEURB (2016) e b) Autores

Figura 3: Adição de detalhes nas colunas principais da fachada não existentes na planta de elevação e na edificação.

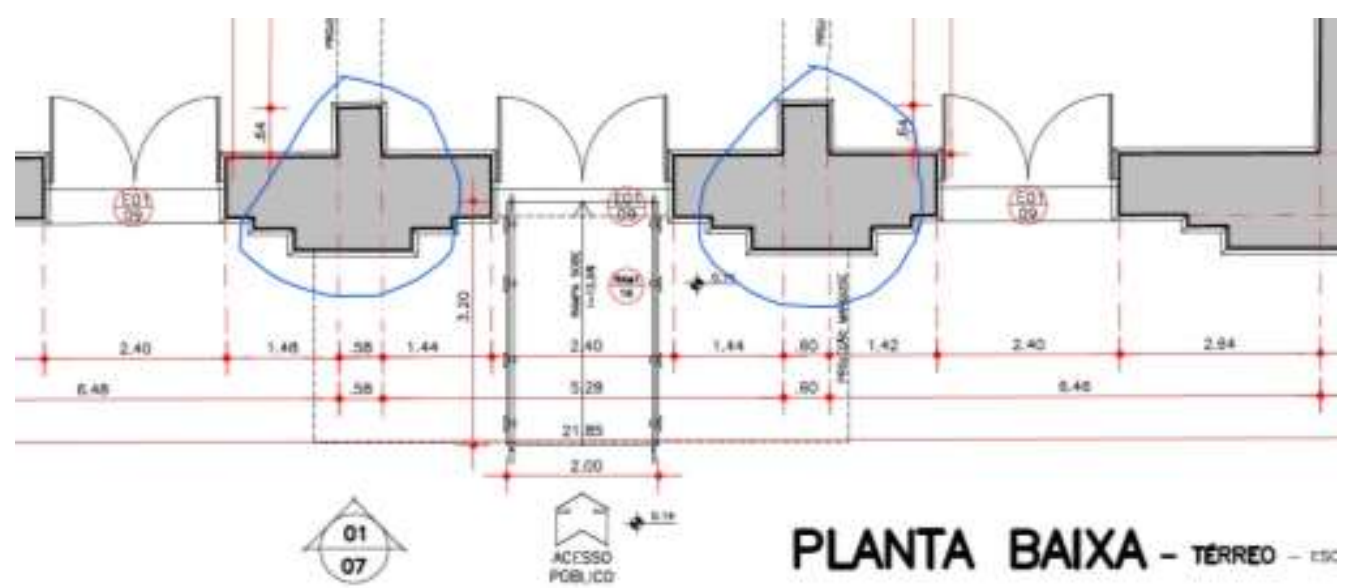

Fonte: SEURB (2016).

As dimensões dos frisos da planta da fachada também possuem divergências, se vistos em planta, possuem a mesma dimensão, mas ao comparar in loco, as dimensões são diferentes. Foi observado também que os detalhes das esquadrias divergem no que foi registrado nas plantas do que foi observado in loco.

Tais divergências observadas foram consideradas durante a modelagem representando o estado atual que a edificação se encontra, conforme constatado in loco.

\subsection{Modelagens dos elementos}

Após análise dos registros fotográficos e de inspeções feitas no prédio sede se deu o início da modelagem do Solar da Beira pelo programa Revit, observa-se a criação das paredes, detalhes arquitetônicos, esquadrias, elementos estruturais e outros elementos que serão apresentados nos próximos subitens.

Para início da modelagem, foi analisado as plantas de cortes para visualizar o nível de cada pavimento e assim fazer a inserção deste no REVIT com suas alturas referentes, sendo inseridos pela "Guia Arquitetura $>$ painel de dados $>$ Nível alocando cada pavimento na altura adequada para criação das plantas. Após isso, foi criado suas plantas baixas por "Guia Vista> painel 
criar> Vistas de planta>Planta de Piso". Com a criação das plantas de piso foi possível iniciar a modelagem e a inserção de itens no projeto (ver Figura 4).

Para a realização da importação das plantas baixas, foi feito "Guia Inserir> Painel de Importar> Importar CAD", configurando as medidas métricas e local de referência para inserção das plantas no REVIT. E assim cada planta baixa de cada pavimento foi alocada de acordo com sua planta de piso do programa, conforme observado na Figura 5.

Figura 4: Inserção de informações de projeto.

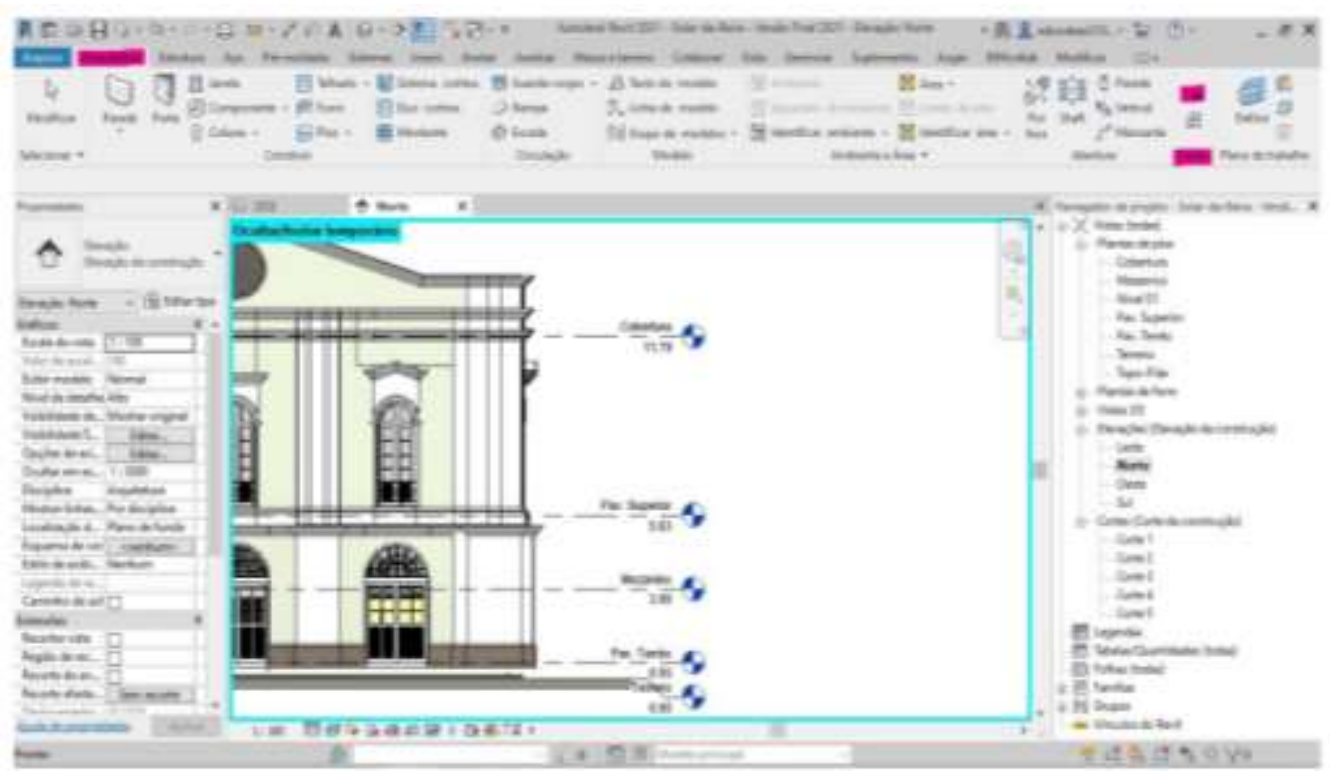

Fonte: Autores.

Figura 5: Importação de plantas baixas para o Revit.

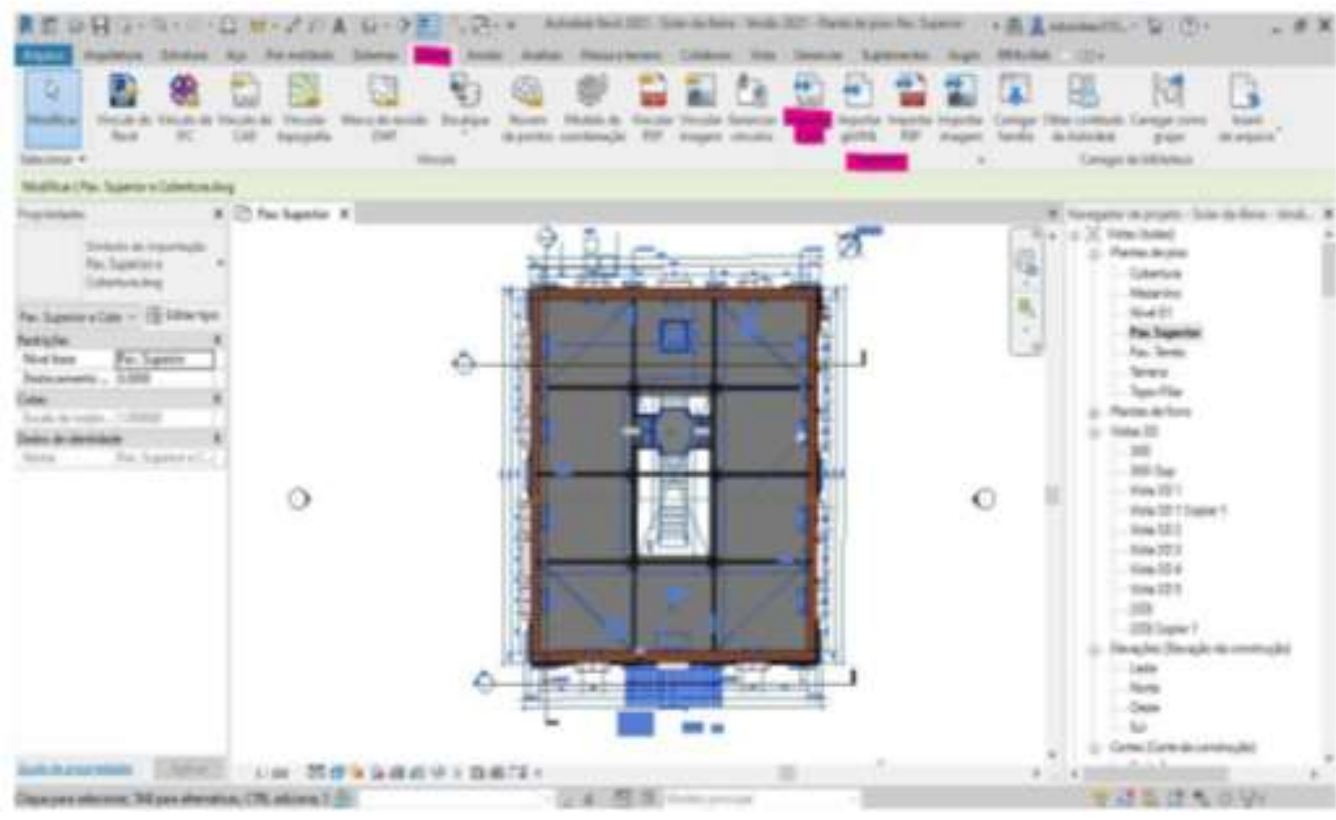

Fonte: Autores. 


\subsection{Modelagens das paredes}

Houve dificuldade na criação das paredes, pois as mesmas apresentavam espessuras diferentes. Tendo em vista a diferenciação entre espessuras, tornou-se necessária a criação de uma parede por via da ferramenta de adição de componentes "Guia arquitetura $>$ Painel Construir $>$ Componente $>$ Modelar no Local $>$ Lista de filtros $>$ Arquitetura $>$ Parede", a partir daí foram utilizadas as ferramentas de modelagem que o Revit fornece. Este tipo de modelagem faz perder a opções de inserção de mais informações como a locação de camadas de outros materiais e informações não gráficas.

Como correção para criar a modelagem, optou-se por utilizar o método de criação de parede cebola que é método em que cada camada construtiva da parede (seja revestimento ou estrutural) é coloca separadamente. Então, foi criada uma parede arquitetônica básica na opção de arquitetura para inserção da camada da pintura externa (Figura 6).

Figura 6: Parede cebola: "Parede" de pintura do projeto selecionada.

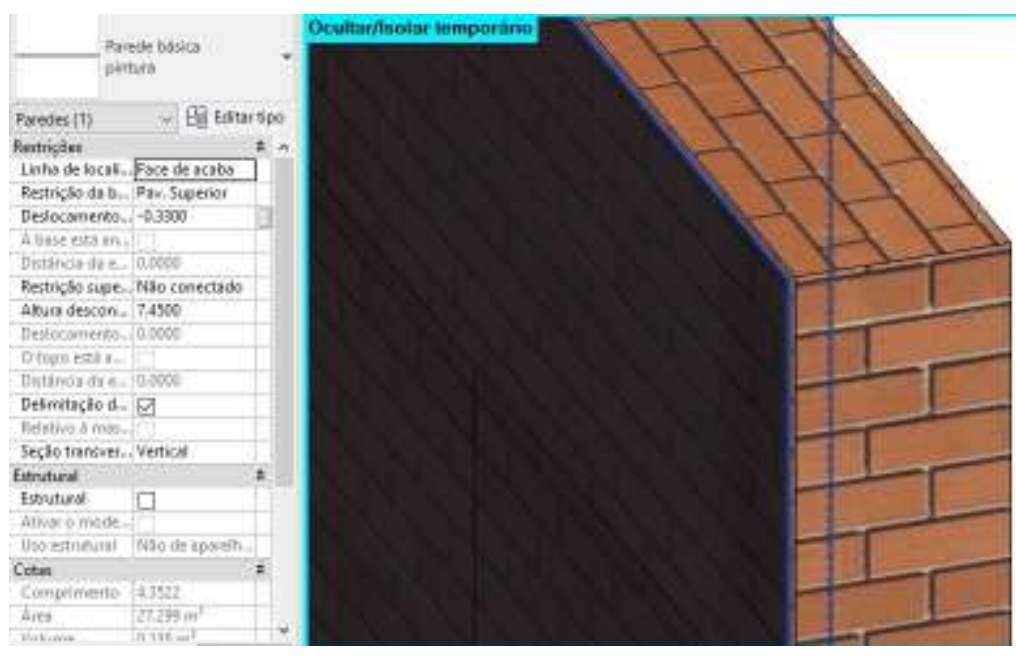

Fonte: Autores.

\subsection{Banheiros}

Os banheiros que se encontram na parte posterior do Solar tiveram suas posições trocadas, não encontrando nenhum registro que explicasse a mudança. Para a modelagem dessa área foram usadas funções da guia arquitetura do programa para criação dos banheiros. A Figura 7 representa a modelagem executada, considerando apenas as informações contidas nas plantas baixas.

Figura 7: Modelagem do banheiro e acordo com planta baixa (sem escala).

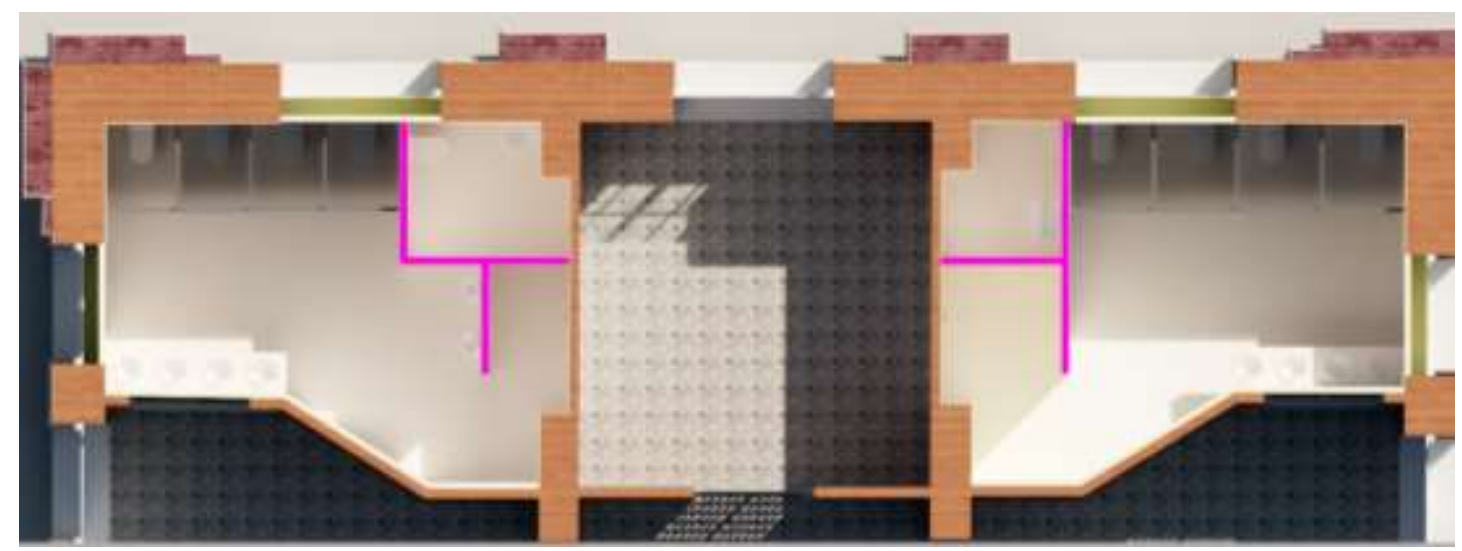

Fonte: Autores. 
A modelagem das áreas dos banheiros foi realizada a partir da inserção de objetos genéricos, como pias, vasos sanitários, mictórios, boxes de banheiro devido ao número de mudanças encontradas em registros.

\subsection{Modelagens das esquadrias}

Para registro das portas seculares da edificação, foi necessária a criação das portas por meio da opção criação de família com a escolha do template (Arquivo base 63 configurados para criação de projetos ou elementos) para criação de família de portas métricas fornecido pelo próprio Revit.

Foram criados 6 modelos de portas referentes às esquadrias presentes no solar com códigos de E01, E02, E03, E04, E05 E07, onde cada uma possui suas especificidades, portanto, são únicas, como por exemplo a porta principal do solar, que é uma adaptação da esquadria E01 (Figura 8). Algumas portas se repetem pela edificação E02, E06 e E07, estas possuem a mesma base de esquadria mudando somente suas molduras externas comparando as plantas de detalhes, enquanto a E02 é a mesma em todas situações (Figura 9).

Figura 8: Modelagem da porta principal (E01).

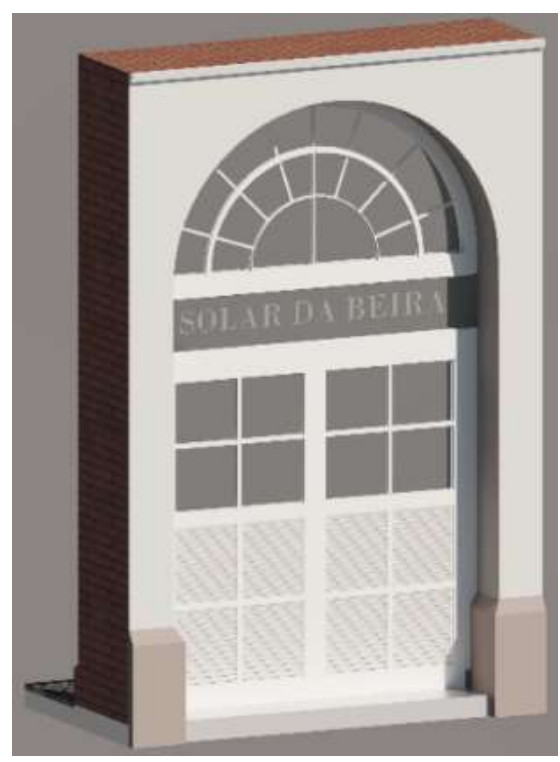

Fonte: Autores.

Figura 9: Modelagem de esquadrias.

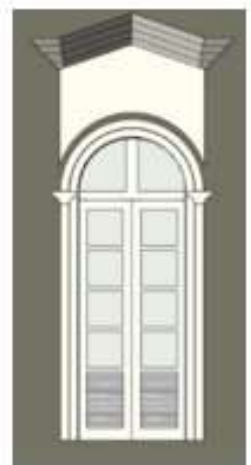

E06

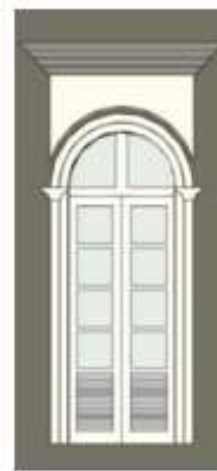

E07

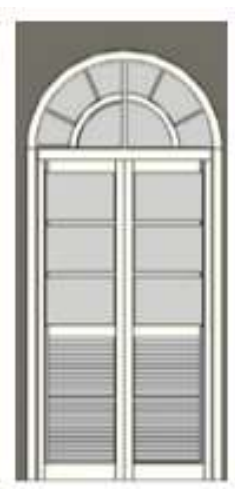

E02

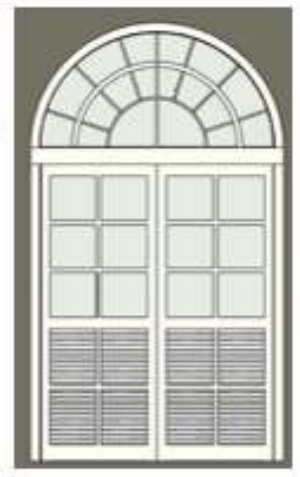

E05

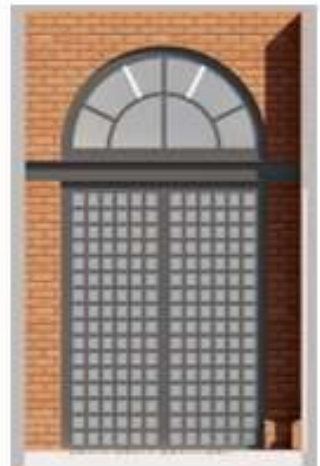

E03 e E04

Fonte: Autores. 
Não foi possível medir in loco as diferenças observadas na E05, deste modo, escolheu-se manter a modelagem para a E01 e E05. As esquadrias E03 e E04 também possuem mesmas características de material e dimensões, tendo como principal diferença a ausência da bandeira na E04.

Nota-se uma diferença significativa nas larguras de algumas peças de madeira existente, todas as esquadrias foram registras com o LOD 300, mesmo possuindo um bom nível de detalhes, por conta de não possuírem desenvolvimento das suas armações (trincos, dobradiças e fechaduras).

\subsection{Modelagem dos elementos estruturais}

Para a criação da tesoura do prédio, foi adaptada uma treliça existente no programa por meio da opção "Guia Estrutura> Painel Estrutura>Treliça" após adição do elemento foi feita sua edição para ficar mais similar ao modelo existente. Foram modelados pilares do pavimento superior também usada a opção de criação de famílias, porém usando o template para criação coluna estrutural métrica.

Para a inserção das vigas metálicas foram usadas modelos existentes nos programas inseridos por meio do "Guia Inserir>Painel Carregar da Biblioteca> Carregar Família" e seguir o caminho de ficheiros. Após adicionar a viga selecionada no corpo do projeto é necessário "chamá-la" pra inserção no projeto pelo caminho a seguir "Guia Estrutura>Painel Estrutura> Viga" e conseguinte editar suas dimensões. Como não foi possível saber o tipo de aço usado, não houve dados suficientes para adicionar as informações morfológicas.

A Figura 10 apresenta os elementos estruturais modelados e seus desenvolvimentos se encontram em LOD 300 justamente por não possuírem um desenvolvimento tão assertivo, mas esse LOD é suficiente para a análise e a manutenção do modelo.

Figura 10: Modelagem dos elementos estruturais.

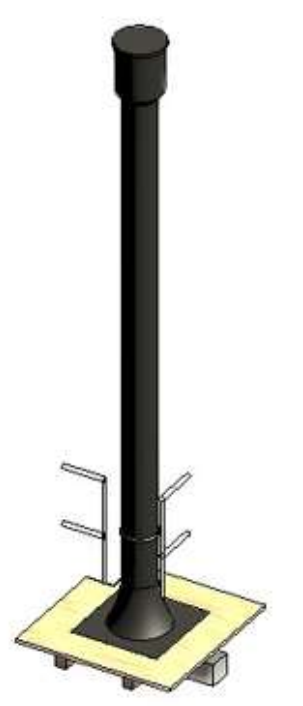

(a) Pilar.

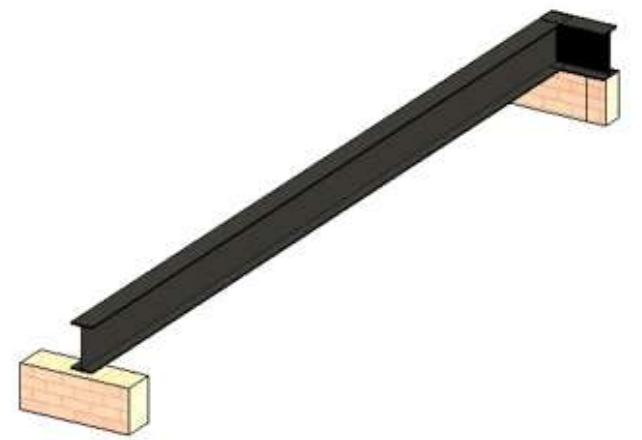

(b) Viga.

Fonte: Autores.

\subsection{Escada e Guarda-corpo}

A escada e os guarda-corpos foram feitos com elementos existentes no Revit, pois não possuem desenvolvimento e nem detalhamento fiel ao real. Elementos como elevador (instalado na última obra do solar da beira) não foram incluídos no modelo, pois seu desenvolvimento requer maior conhecimento de modelagem em programas BIM. 
Para a criação dos patamares da escada foram criados níveis auxiliares (início da escada, $1^{\circ}$ patamar e $2^{\circ}$ patamar) para melhor elaboração do elemento.

A criação da escada foi feita pelo caminho a seguir "Guia Arquitetura>Painel Circulação>Escada" e a do guarda corpo: "Guia Arquitetura>Painel Circulação>Guarda- 71corpo" e a inserção do guardo-corpo varia entre a opção planta por croqui ou inserir em rampas ou escadas. A Figura 11 apresenta a modelagem da escada.

Figura 11: Modelagem da escada.

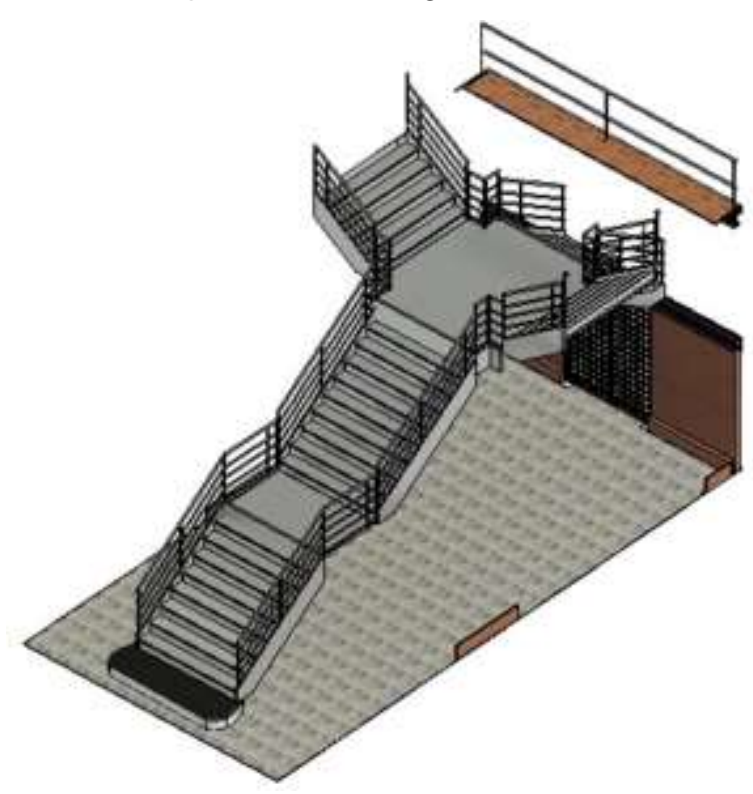

Fonte: Autores.

\subsection{Modelagem da cobertura e piso}

A cobertura do prédio foi modelada com a função telhado (Guia Arquitetura>Painel Construir>Telhado> Por perímetro), usando-se como base as dimensões encontradas nas plantas baixas, bem como a inclinação do telhado (Figura 12). Para representar o telhado usou-se material "telha cerâmica" do próprio do programa. O Lanternim foi modelado de acordo com dados também presentes nas plantas fornecidas.

Para a estrutura de ripas e caibros da cobertura e as vigas de madeira do piso superior usou-se a função "sistema de vigas" (Guia Estrutura $>$ Painel Estrutura $>$ Sistema de Vigas). A escolha do material das vigas foi feita conforme explicado no tópico anteriormente. Todos os elementos da cobertura e do piso superior foram criados sem muita dificuldade. Os coletores de água pluvial não foram modelados devido ao alto grau de detalhamento.

A inserção do piso em todos os pavimentos foi feita pelo "Guia Arquitetura>Painel Construir>Piso". A paginação do piso inferior foi feita através de uma imagem tirada do ladrilho hidráulico e inserida pela opção de criação de material "Guia Gerenciar>Painel Configurações>Materiais". Depois o material foi selecionado e escolhido, editando-se sua aparência. 


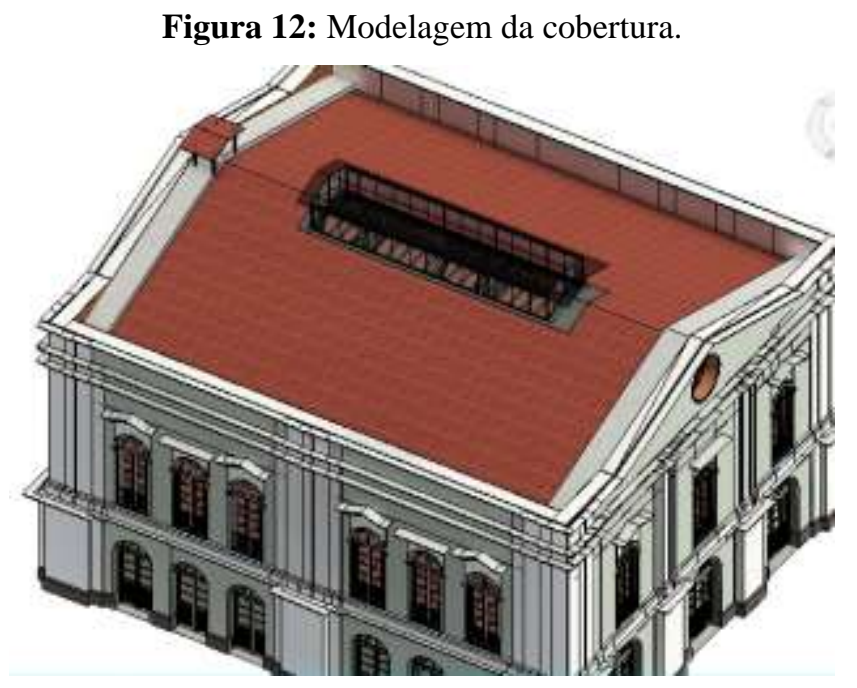

Fonte: Autores.

\subsection{Fachadas e cortes}

Para o desenvolvimento das fachadas, utilizou-se como base as plantas de elevação para iniciar os detalhamentos e durante o desenvolvimento notou-se diferenças entre o registrado e o real, com falta de detalhes nos documentos, como já citado anteriormente, sendo necessário comparar com registro fotográfico para analisar tais divergências. Também se observou diferença de dimensões entre as molduras construídas e as plantas de elevação. Para a fluidez da modelagem utilizou-se de dimensões iguais entre todas, já que não foi possível medir as molduras, devido à altura em que se encontravam e à falta de nenhum equipamento de altura para desempenhar tal ação.

As plantas de corte foram essenciais para a análise de altura de piso melhorando o entendimento de suas composições, sendo que a partir delas se conseguiu desenvolver boa parte do trabalho com êxito, pois permitiram captar com melhor eficiência e eficácia os detalhes construtivos.

A seguir estão as modelagens finais (Figuras 13 a 16) geradas junto com ao programa utilizado para a precisão da modelagem feita do Solar da Beira.

Figura 13: Perspectivas do Solar a Beira.

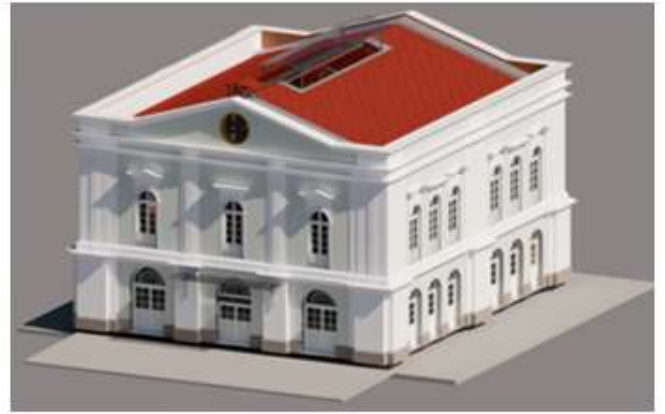

(a) Solar da Beira Perspectiva 01.

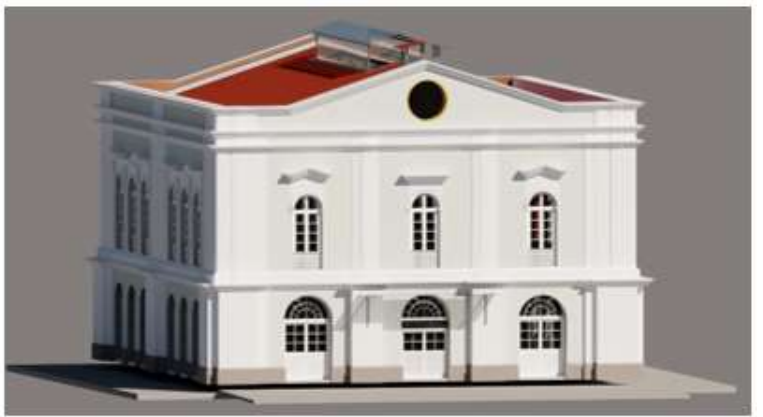

(b) Solar da Beira Perspectiva 02.

Fonte: Autores. 
Research, Society and Development, v. 11, n. 1, e51311125169, 2022

(CC BY 4.0) | ISSN 2525-3409 | DOI: http://dx.doi.org/10.33448/rsd-v11i1.25169

Figura 14: Cortes.

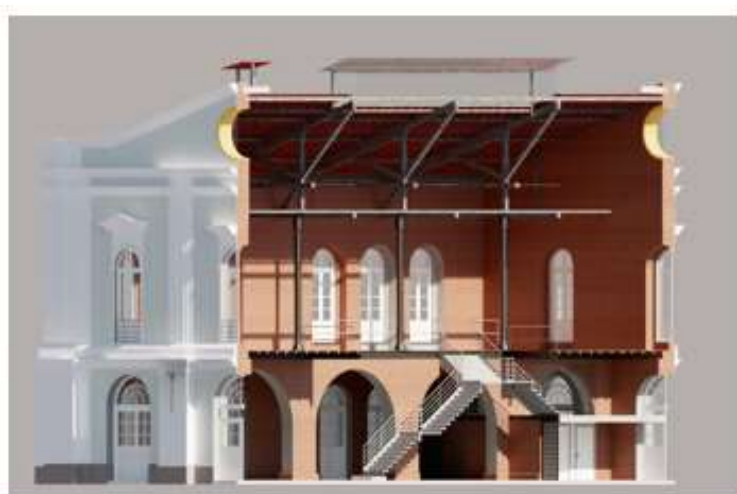

(a) Corte longitudinal.

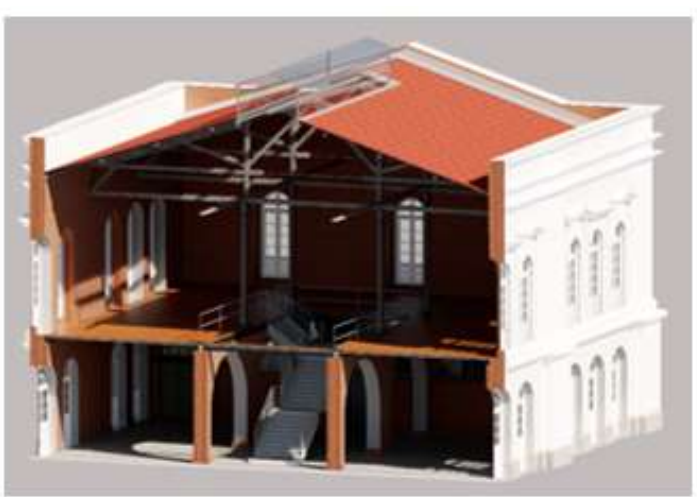

(b) Corte transversal.

Fonte: Autores.

Figura 15: Vista superior.

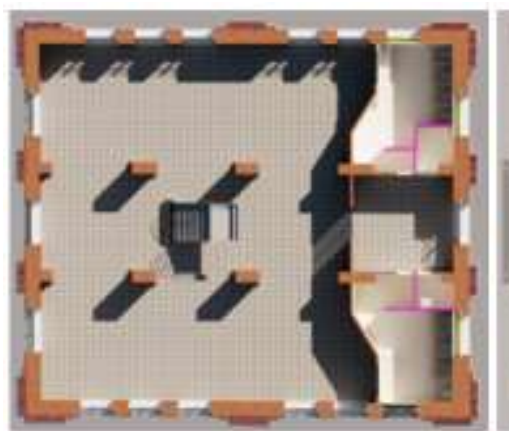

(a) Pavimento térreo.

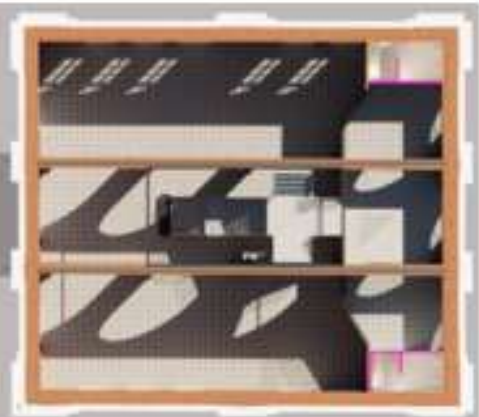

(b) Mezanino.

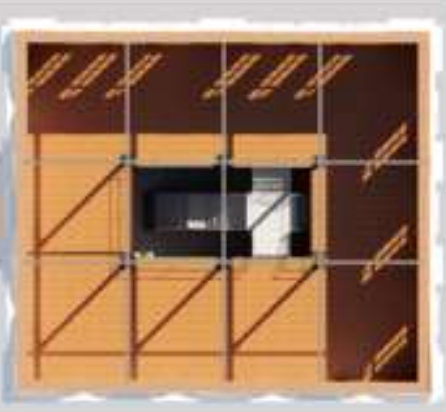

(c) Pavimento superior.

Fonte: Autores.

Figura 16: Imagens representativas.

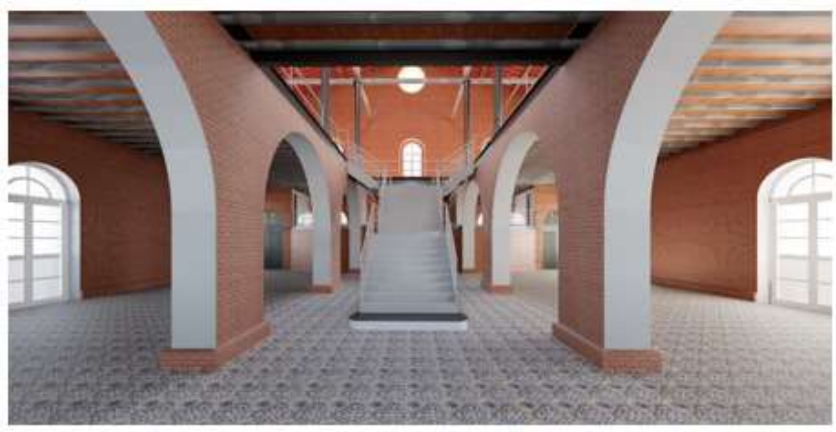

(a) Pavimento térreo.

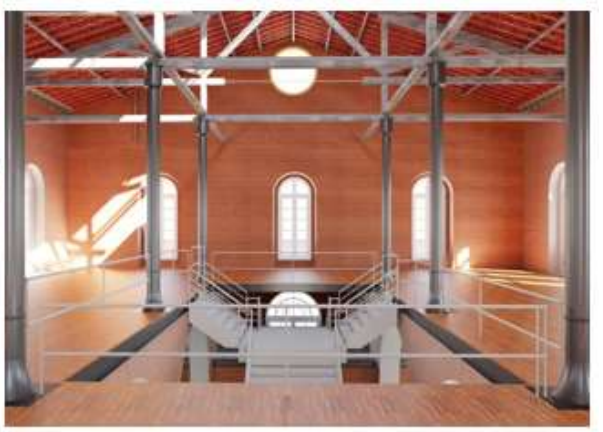

(b) Pavimento superior.

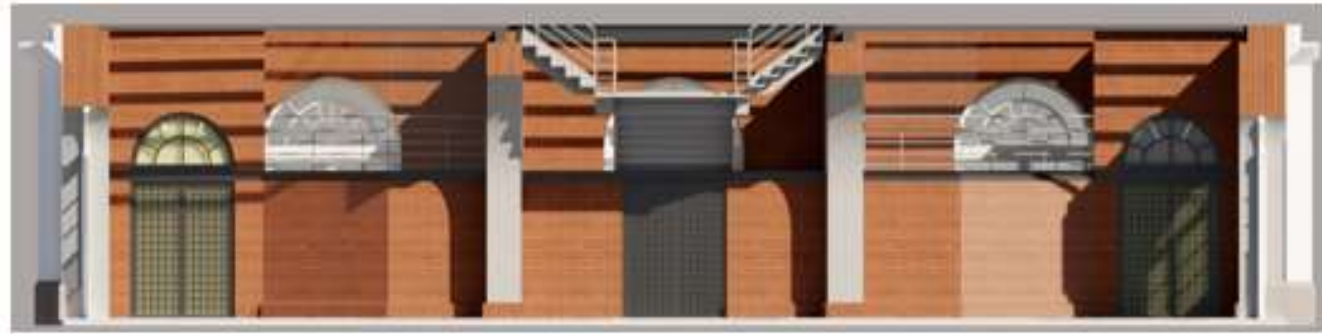

(c) Vista frontal (mezanino e térreo).

Fonte: Autores. 


\section{Conclusão}

Os resultados demonstram as facilidades e dificuldades que essa metodologia pode oferecer na conservação e restauro do patrimônio histórico. As famílias incluídas nesse estudo correspondem ao nível de detalhamento LOD300. Ainda, a pesquisa demonstra algumas imprecisões entre projeto e execução, como por exemplo, diferenças no detalhamento arquitetônico entre os cortes e fachadas com o edifício construído.

No entanto, apesar dos desafios encontrados nas modelagens das famílias, foi atingido o objetivo de realizar, com certa precisão a modelagem do prédio do Solar da Beira e, embora não contando com a elaboração de todo o detalhamento presente nas plantas, foi possível obter um bom desenvolvimento e representação no modelo tridimensional e mostrar os dados construtivos da edificação. Nesse sentido, nota-se a relevância de maior conhecimento para uma modelagem BIM mais completa da edificação.

É notório que os dados aqui fornecidos facilitam tanto o estudo do Solar da Beira quanto os planejamentos para futuras intervenções e preservação do prédio.

Em relação ao HBIM, este expõe sua importância na união entre tecnologias e estudo histórico social de edificações, ao passo que possibilita maior precisão nos serviços a serem executados, evitando gastos desnecessários e possíveis danos e garantindo, assim, um restauro seguro e eficiente e, como efeito, um bom desempenho e extensão na vida útil da edificação.

Por fim, o material produzido colabora com a biblioteca de dados HBIM, de fácil acesso, facilitando assim a documentação, análise e conservação do patrimônio edificado.

Como sugestão para trabalhos futuros, pode-se utilizar de maneira conjunta outros programas BIM para criação de um arquivo BCF com o intuito de registrar todas as mudanças que o prédio passou e há de passar com o tempo, em formato de relatório dinâmico. Assim como modelar os projetos complementares para uma maior integração ou reproduzir o Solar da Beira em outros programas de modelagens para confrontar quais dos programas possuem maior usabilidade para registros de prédios históricos e melhorar a difusão do HBIM no Brasil.

\section{Referências}

Almeida, A., \& Inojosa, L. (2021). HBIM - Modelagem De Informação Para Preservação De Patrimônio. Congresso Internacional sobre Patologia e Reabilitação das Construções. Ceará.

Amorim, A. L. (2008). Documentação do Patrimônio Arquitetônico do estado da Bahia com tecnologias digitais. In: Computação gráfica: pesquisas e projetos rumo à Educação Patrimonial.

Amorim, A. L., Groetelaars, N. J. \& Lins, E. A., (2008). Um centro de documentação do patrimônio arquitetônico. In: Fórum Patrimônio: ambiente construído e patrimônio sustentável, 2(2): 194-206.

Costa, H. Á., Souza, M. P., Baldessin, G.Q., Albano, G. \& Fabricio, M. M., (2021). Modelagem BIM para o registro digital do Patrimônio Arquitetônico Moderno. Revista Projetar, 6(1): 49-68.

Couceiro \& Rubim (2016). Restauração Solar da Beira: Projeto executivo. Pranchas, 19. Secretaria Municipal de Urbanismo (SEURB) - Prefeitura de Belém.

Coutinho, A. B., Moura, G. S. \& Teixeira, E. K. C., (2021). Compatibilização de um projeto arquitetônico e hidrossanitário utilizando a metodologia BIM. Research, Society and Development, 10(02).

Dore, C. \& Murphy. M., (2012). Integration of Historic Building Information Modeling (HBIM) and 3D GIS for recording and managing cultural heritage sites. In: Conferência Internacional sobre Sistemas Virtuais e Multimídia. Milan.

Eastman, C., (1975). The Use of Computers Instead of Drwaings In Building Design. AIA Journal, 36(3): 46-50.

Eastman, C., Teicholz, P., Sacks, R., \& Liston, K., (2014). Manual de BIM: um guia de modelagem da informação da construção para arquitetos, engenheiros, gerentes, construtores e incorporadores (1a ed.). Rio Grande do Sul: Bookman.

Godinho, E. (2017). A invenção do Centro Histórico de Belém/PA: Aspectos institucionais. In: Encontro Nacional da Associação Nacional de PósGraduação e Pesquisa em Planejamento Urbano e Regional. São Paulo.

IPHAN (2018). Lista de bens tombados processos andamento 2018.

Kamardeen, I., (2010). 8D BIM Modelling tool for accident prevetion through. Annual ARCOM Conference, 281-289. Leeds. 
Research, Society and Development, v. 11, n. 1, e51311125169, 2022

(CC BY 4.0) | ISSN 2525-3409 | DOI: http://dx.doi.org/10.33448/rsd-v11i1.25169

Nora, R., (2015) Curso de extensão e aperfeiçoamento em gestão cultural - I Etapa a distância: Aula 3: Patrimônio Cultural Material e Imaterial.

Nunes, M. (2017). Rumo ao Boulevard da República: Entre a cidade imperial e a metrópole Republicana (Tese de doutorado). Universidade Federal do Pará, Belém, Pará, Brasil.

Pereira, J. M. (2015). O uso da tecnologia BIM em patrimônio histórico, um caso de estudo: o convento dos capuchos da Caparica (Almada) (Dissertação de Mestrado). Instituto Superior Técnico. Lisboa, Portugal.

Rocha, J. \& Tomé, A. (2020). Multidisciplinaridade e acessibilidade na representação patrimonial em HBIM. In: Congresso Português de Building Information Modelling. Porto.

Seabra, A., (2020). Relatório Final: Projeto de Acompanhamento Arqueológico e Arqueologia Pública nas Obras de Reforma e Restauro do Solar da Beira.: Instituto do Patrimônio Histórico e Artístico Nacional.

Silva, T., et al., (2019) BIM (8D) Como ferramenta de gestão em segurança ocupacional: Perspectivas de uso. In: Simpósio brasileiro da qualidade do projeto no ambiente construído. Uberlândia.

Smith, P., (2014). BIM implementation: global strategies. Creative Construction Conference, 85(1), 482-492.

Tolentino, M. (2018). A utilização do HBIM na documentação, na gestão e na preservação do Patrimônio Arquitetônico (Tese de doutorado). Universidade Federal da Bahia. Salvador, Bahia, Brasil.

Tonini, M. \& Oliveira, F. (2016). A importância do plano de conservação programado para preservação de edifícios modernos. In: Congresso IberoAmericano Património, suas matérias e imatérias. Lisboa.

Toscano, T. (2016). Consultoria em restauro: Solar da Beira - Memorial descritivo: Subsídios restaurativos para projeto de arquitetura. Instituto do Patrimônio Histórico e Artístico Nacional. 